Int. J. Electrochem. Sci., 14 (2019) $3764-3776$

\title{
Comparative Study on Voltammetric and Spectrofluorimetric Methods for Fluorescein Detection
}

\author{
Agnieszka Paziewska-Nowak ${ }^{*}$, Marek Dawgul, Dorota G. Pijanowska \\ Department of Hybrid and Analytical Microbiosystems, Nalecz Institute of Biocybernetics and \\ Biomedical Engineering, Polish Academy of Sciences, Ks. Trojdena 4 St., 02-109 Warsaw, Poland \\ *E-mail: apaziewska@ibib.waw.pl
}

doi: 10.20964/2019.04.07

Received: 30 October 2018 / Accepted: 7 January 2019 / Published: 10 March 2019

The aim of this research was assessment of suitability of both methods voltammetric and spectrofluorimetric to fluorescein detection. Electrochemical activity of the analyte was examined in the supporting electrolytes of three different $\mathrm{pH}$ values due to a strong dependence of fluorescein properties on $\mathrm{pH}$ of the sample. Moreover, the electrochemical behavior of fluorescein was studied using different materials of working electrode - graphite paste, graphene paste and glassy carbon. Experiments performed using voltammetric methods indicated that fluorescein is electrochemically active. The influence of $\mathrm{pH}$ on its electrochemical activity was confirmed. Fluorescein undergoes oneor two-step irreversible electrochemical oxidation in the considered potential range from 0 to $+1.4 \mathrm{~V}$, exhibiting the decrease of peak current with the increase of sample $\mathrm{pH}$. Differential pulse voltammetric measurements enabled successful detection of fluorescein at micromolar concentration levels at graphene and graphite sensors, with the following limit of detection values: for graphene sensors $7.4 \mu \mathrm{M}$ at $\mathrm{pH} 4.5,34.55 \mu \mathrm{M}$ at $\mathrm{pH} 7,23.42 \mu \mathrm{M}$ at $\mathrm{pH}$ 9; for graphite sensors $6.44 \mu \mathrm{M}$ at $\mathrm{pH} 4.5$, $42.27 \mu \mathrm{M}$ at $\mathrm{pH} 7,95.12 \mu \mathrm{M}$ at $\mathrm{pH}$ 9, whereas results obtained using glassy carbon electrodes were less satisfactory. Comparative study of electrochemical and optical methods for fluorescein detection indicated voltammetry as more suitable for measurements in the acidic solutions, whereas spectrofluorimetry was more advantageous in the case of alkaline media. Thus, we conclude that for quantitative detection of fluorescein in aqueous solutions, both voltammetric and spectrofluorimetric methods are suitable, since complement each other - when associated, they allow to detect fluorescein in wide $\mathrm{pH}$ range. On the basis of the obtained results we stated that $\mathrm{pH}$ value of the sample affects the utility of each method due to its effect on electrochemical and optical features of fluorescein. Therefore, when choosing the most adequate method - electrochemical or optical, for measurements based on fluorescein detection, $\mathrm{pH}$ of the sample should be taken into account, primarily.

Keywords: electrochemical activity; fluorescein; voltammetry; spectrofluorimetry; thick-film amperometric electrodes. 


\section{FULL TEXT}

(C) 2019 The Authors. Published by ESG (www.electrochemsci.org). This article is an open access article distributed under the terms and conditions of the Creative Commons Attribution license (http://creativecommons.org/licenses/by/4.0/). 